\title{
Relações de saber e poder na Educação a Distância: uma análise sobre a Universidade Aberta do Brasil
}

\section{Relationships of knowledge and power in Distance Education: an analysis of the Universidade Aberta do Brasil}

\author{
Relaciones de saber y poder en la Educación a Distancia: \\ un análisis sobre la Universidade Aberta do Brasil
}

\author{
Braian Garrito Veloso ${ }^{1}$ \\ http://orcid.org/0000-0002-9459-5740
}

Daniel Mill ${ }^{2}$

http://orcid.org/0000-0002-8336-3645

\begin{abstract}
Resumo: O objetivo principal deste artigo é discutir as relações hierárquicas e suas implicações nas relações de saber e poder no trabalho docente exercido na Educação a Distância (EaD), no âmbito do Sistema Universidade Aberta do Brasil (UAB). Este que é, atualmente, a mais vultosa política pública de educação superior a distância do País. Para atender ao escopo do estudo, lançamos mão dos métodos quantitativo e qualitativo. Com relação aos procedimentos metodológicos, foram coletados dados, por meio de questionários virtuais, de 677 docentes que atuam ou já atuaram no âmbito do Sistema UAB. Posteriormente, foram realizadas entrevistas semiestruturadas com 8 desses profissionais. Por meio desta pesquisa, identificamos características de uma gestão menos centralizada no bojo da docência exercida na EaD. Isso implica um trabalho mais cooperativo e interdependente. Contudo, também foram identificadas relações hierárquicas bastante nítidas e percebidas pelos profissionais. De sorte que nossa pesquisa apresenta indícios e hipóteses de que essas relações incidem sobre aquelas de saber e, por conseguinte, poder que se estabelecem no cerne da polidocência.
\end{abstract}

1 Mestre e doutorando pelo Programa de Pós-Graduação em Educação (PPGE) da Universidade Federal de São Carlos (UFSCar). Membro do Grupo de Estudos e Pesquisas sobre Inovação em Educação, Tecnologias e Linguagens (Grupo Horizonte) da UFSCar. Suas pesquisas têm ênfase na Educação a Distância (EaD) e no trabalho docente exercido nessa modalidade.

2 Professor da Universidade Federal de São Carlos (UFSCar), onde trabalha como Docente e Gestor de Educação a Distância (EaD). Doutor em Educação pela UFMG, com pós-doutorado pelas Universidade de Coimbra e Universidade Aberta de Portugal. É membro do Programa de Pós-Graduação em Educação e do Programa de Pós-Graduação em Ciência, Tecnologia e Sociedade. É Líder do Grupo Horizonte (Grupo de Estudos e Pesquisas sobre Inovação em Educação, Tecnologias e Linguagens) e, como pesquisador, tem interesse particular pela interseção das temáticas: Trabalho Docente, Tecnologias, Linguagens, Cognição e Educação a Distância. 
Palavras-chave: Educação a Distância. Trabalho Docente. Relações de Saber. Relações de Poder. Sistema Universidade Aberta do Brasil.

\begin{abstract}
The main objective of this article is to discuss the hierarchical relations and their implications in the relations of knowledge and power in the teaching work carried out in Distance Education, within the scope of the Universidade Aberta do Brasil (UAB) system. This is currently the most important public policy in higher distance education of the country. In order to meet the scope of the study, we use quantitative and qualitative methods. Regarding the methodological procedures, data were collected, through virtual questionnaires, of 677 teachers who work or have already worked under the UAB System. Subsequently, semi-structured interviews were conducted with 8 of these professionals. Through this research, we identify characteristics of a less centralized management in the teaching of the Distance Education. This implies a more cooperative and interdependent work. However, hierarchical relationships were also clearly found and perceived by professionals. So our research presents clues and hypotheses that these hierarchical relations affect those of knowledge and power that are established at the core of polidocência.
\end{abstract}

Keywords: Distance Education. Teaching Work. Knowledge Relations. Power Relations. Universidade Aberta do Brasil System.

Resumen: El objetivo principal de este artículo es discutir las relaciones jerárquicas y sus implicaciones en las relaciones de saber y poder en el trabajo docente ejercido en la Educación a Distancia (EaD), en el ámbito del Sistema Universidade Aberta de Brasil (UAB). Este es, actualmente, la más amplia política pública de educación superior a distancia del país. Para atender lo objetivo, utilizamos los métodos cuantitativo y cualitativo. Con respecto a los procedimientos metodológicos, fueron recolectados datos, por medio de cuestionarios virtuales, de 677 docentes que actúan o ya actuaron en el ámbito del Sistema UAB. Posteriormente, se realizaron entrevistas semiestructuradas con 8 de esos profesionales. Por medio de esta investigación, identificamos características de una gestión menos centralizada en la docencia ejercida en la EaD. Esto implica un trabajo más cooperativo e interdependiente. Sin embargo, también se identificaron relaciones jerárquicas bastante nítidas y percibidas por los profesionales. De suerte que nuestra investigación presenta indicios e hipótesis de que esas relaciones tiene efecto sobre las relaciones de saber $y$, por consiguiente, de poder que se establecen en el núcleo de la polidocência.

Palabras clave: Educación a distancia. Trabajo de Enseñanza. Relaciones de Saber. Relaciones de Poder. Sistema Universidade Aberta do Brasil.

\title{
1 INTRODUÇÃO
}

Este artigo traz uma análise diretamente enfocada no trabalho docente exercido na Educação a Distância $(\mathrm{EaD})$. Mais especificamente, pretendemos analisar as relações de hierarquia e, consequentemente, aquelas de saber e poder que se estabelecem no seio do trabalho polidocente no âmbito do Sistema Universidade Aberta do Brasil (UAB). Parece-nos que, a partir da forma como a docência na EaD se configura na contemporaneidade, isto é, divida e fragmentada, engendram-se complexas relações hierárquicas que têm que ver com aquelas de saber e poder estabelecidas entre os educadores. Sendo assim, ao compreendermos que a atividade docente no âmbito do Sistema UAB implica num trabalho cooperativo, mas também fragmentado, interessa-nos desvelar as implicações daí recorrentes no que respeita às relações entre saber e poder dos profissionais. 
Salientamos que o foco desta investigação é o Sistema UAB, pois este é um dos principais responsáveis pelo crescimento da EaD no Brasil. Além disso, consideramos que, sob a forma como ele foi estruturado, cria-se um terreno fértil para o desenvolvimento de características imanentes às relações hierárquicas. Portanto, analisaremos dados coletados com profissionais docentes que atuam ou já atuaram em cursos a distância oferecidos por meio do Sistema UAB à luz de discussões teóricas enfocadas nas relações de hierarquia e naquelas de saber e poder no bojo da polidocência.

No que se refere à estrutura do texto, inicialmente abordamos a definição de EaD adotada no artigo. Em seguida, tratamos sobre a metodologia e os procedimentos metodológicos utilizados na coleta de dados. Após isso, iniciamos as análises enfocadas nas relações de hierarquia que se estabelecem na polidocência. Posteriormente, partimos à discussão sobre as relações de saber e poder para, por fim, estabelecermos algumas considerações finais para o estudo.

\section{EDUCAÇÃO A DISTÂNCIA E POLIDOCÊNCIA}

Como ponto de partida, propomo-nos a definir o que entendemos por Educação a Distância (EaD). Parece-nos lógico elucidar, a priori, nossa definição sobre a modalidade para, em seguida, compreendermos a forma como ocorre o trabalho docente nos cursos a distância. Uma vez que tais considerações se mostram como condição sine qua non para o entendimento das reflexões que faremos no decorrer do texto, estabeleceremos algumas precisões teóricas para situar, neste primeiro momento, a nossa perspectiva de análise.

Para Neves (2016), a EaD acontece mediante a separação física entre os atores envolvidos no processo de ensino-aprendizagem, estabelecendo uma relação de comunicação e aprendizagem multidirecional. Ainda para essa autora, trata-se de um modelo que pode ser organizado a fim de possibilitar ao discente a reconstrução do conhecimento por meio de sua própria experiência (NEVES, 2016).

Sob o entendimento de Kenski (2013), enquanto a educação presencial é definida pela sala de aula e todos os recursos físicos, humanos e tecnológicos restritos à área física em que ela e situa, a EaD se apresentam em um não-lugar, um espaço virtual indeterminado. Isto é, ela apresenta, como característica fundamental, a proposta de ensinar e aprender sem que haja necessidade de professores e alunos estarem no mesmo local ao mesmo tempo (MILL, 2012). Exatamente por isso, entende-se que:

[...] Para que a aprendizagem ocorra, são utilizadas diferentes tecnologias e ferramentas, como programas computacionais, livros, CD-ROMs e recursos da internet, disponíveis no ambiente virtual de aprendizagem (AVA) etc. Assim, a interlocução é possibilitada tanto por suportes tecnológicos para comunicação síncrona/simultânea (como em webconferências, salas de bate-papo, etc.) quanto para comunicação assíncrona/diferida (a exemplo de fóruns, ferramentas para edição de textos 
web e e-mails). Em suma, a EaD na contemporaneidade é uma modalidade educacional que geralmente faz uso intensivo de tecnologias telemáticas (baseadas nas telecomunicações e na informática) e tem grande potencial para atender a pessoas em condições desfavoráveis para participação em cursos presenciais de graduação ou formação continuada, geralmente oferecidos em grandes centros de pesquisa e difusão de conhecimentos, como é o caso das instituições de ensino superior público do Brasil (MILL, 2012, p. 23).

O que precede nos permite depreender que a EaD é marcada pelo uso intenso de tecnologias de informação e comunicação que, na contemporaneidade, passam a ser preponderantemente digitais. Portanto, embora existam matizes nas conceituações e nos diferentes modelos de EaD, entendemos que a modalidade é caraterizada pela separação geográfica e temporal dos atores envolvidos no processo de ensino-aprendizagem. E para que as distâncias sejam sobrepujadas, lança-se mão de diferentes Tecnologias Digitais de Informação e Comunicação (TDIC). Destacamos que, neste texto, entendemos as tecnologias digitais como indissociáveis ${ }^{3}$ às experiências contemporâneas de EaD no Brasil, sobretudo aquelas situadas no âmbito do Sistema UAB.

Para além dessas especificidades que determinam a modalidade, existem outras que dizem respeito, em especial, à organização do trabalho docente. $\mathrm{Na}$ EaD, diferentemente do ensino presencial, não apenas um, mas vários profissionais devem atuar em consonância para garantir os processo de ensino-aprendizagem. Esse conjunto articulado de trabalhadores, necessário à realização das atividades na EaD, denomina-se polidocência. No entanto, este termo não é a própria docência, mas sim uma forma de analisá-la em suas particularidades (MILL, 2014). Mas nem todos os profissionais que compõem a equipe polidocente são considerados, de fato, educadores. "Geralmente, o docente-autor, o docenteformador e os docentes-tutores são tipicamente educadores. Os outros são profissionais que participam da polidocência e influenciam a qualidade do ensino-aprendizagem, mas não são docentes" (MILL, 2014, p. 37).

Posto isso, salientamos que nossa investigação enfoca apenas os profissionais considerados docentes no contexto do trabalho coletivo da EaD. Nomeadamente, este artigo traz dados coletados com docentes-formadores/aplicadores, docentes-autores/conteudistas e docentes-tutores virtuais e presencias que atuam ou já atuaram em cursos oferecidos no âmbito do Sistema UAB. Nesse sentido, como educadores que, mediante a divisão das atividades, devem se encarregar, em conjunto, pelo processo de ensino-aprendizagem, supomos que no seio do trabalho polidocente se estabelecem relações

3 Ora, não desconsideramos que a modalidade é marcada historicamente pela utilização de diferentes tecnologias que não as digitais. Além disso, no âmbito do Sistema UAB há um amálgama de diferentes recursos tecnológicos que, juntos, compõem o processo de ensino-aprendizagem. Isso significa que não são usadas apenas tecnologias digitais, como o computador e a Internet. Mas estas são ferramentas essenciais ao desenvolvimento da EaD no Brasil e à forma como a modalidade tem se estruturado atualmente. Por isso, acreditamos que não seja possível falar em experiências contemporâneas de cursos a distância sem considerar as TDIC. 
hierárquicas. Estas estão, por sua vez, intrinsecamente ligadas à forma como o Sistema UAB foi constituído, compreendendo profissionais com formações distintas e que atuam em regimes contratuais dissímeis. À guisa de exemplo, docentes-tutores (presenciais e virtuais) atuam, por praxe, como bolsistas, sem quaisquer vínculos empregatícios para com a instituição mantenedora do curso. Em contrapartida, docentes-autores/conteudistas e docentes-formadores/aplicadores são, por vezes, professores da universidade que passam a atuar também na EaD ${ }^{4}$.

Assim, presumimos que as diferentes características que permeiam a atividade docente nos cursos a distância, concomitantemente às distintas funções e formações de cada profissional, incorrem, por vezes, em intricadas relações hierárquicas no seio da polidocência. Consequentemente, têm-se relações de poder indissociáveis às de saber, haja vista a multiplicidade de profissionais, com titulações e conhecimentos diversos, que devem atuar em consonância para garantir a qualidade do processo de ensino-aprendizagem. Quer dizer, pois, que além da divisão e fragmentação do trabalho, a polidocência compreende relações de hierarquia atinentes àquelas de saber e poder na EaD. É sob tais conjecturas que nos propomos a discutir os dados coletados em nossa pesquisa. Porém, antes das discussões teóricas, trataremos, a seguir, da metodologia e dos procedimentos metodológicos da investigação.

\section{METODOLOGIA E PROCEDIMENTOS METODOLÓGICOS}

Esta pesquisa é um recorte da dissertação de mestrado intitulada de "Organização do Trabalho Docente na Educação a Distância: implicações da polidocência no contexto da Universidade Aberta do Brasil (UAB)". Trata-se de um estudo desenvolvimento no âmbito do Grupo Horizonte (Grupo de Estudos e Pesquisas sobre Inovação em Educação, Tecnologias e Linguagens) da Universidade Federal de São Carlos (UFSCar). Portanto, concerne aos esforços deste mesmo Grupo no que diz respeito à compreensão da EaD e os meandros que perpassam as propostas de ensino-aprendizagem na modalidade.

Naquilo que toca à metodologia da pesquisa, o objetivo central deste estudo foi investigar as relações de hierarquia no contexto da polidocência e sua relação com aquelas de saber e poder entre os docentes. Assim, para atendermos este objetivo, utilizamos os métodos quantitativo e qualitativo, pois ambos podem combinar-se de diferentes formas numa mesma investigação (DUARTE, 2009). A essa combinação de múltiplos métodos para estudar um mesmo problema de pesquisa, denomina-se triangulação metodológica (DUARTE, 2009). Sendo assim, Silva (1998, p. 18) considera que:

4 Na dissertação de mestrado intitulada "Organização do Trabalho Docente na Educação a Distância: implicações da polidocência no contexto da Universidade Aberta do Brasil (UAB)" (VELOSO, 2018), abordamos esses aspectos de maneira mais aprofundada. 
A relação desejada entre o quantitativo e o qualitativo pode ser considerada complementar. Ou seja, enquanto o quantitativo se ocupa de ordens de grandezas e as suas relações, o qualitativo é um quadro de interpretações para medidas ou a compreensão para o não quantificável.

As considerações supramencionadas permitem-nos inferir que a convergência entre os métodos qualitativo e quantitativo pode ser profícua na medida em que permite uma abordagem multifacetada do fenômeno a ser investigado. Para Duarte (2009), ambos os métodos podem ser utilizados lado a lado ou simultaneamente. Acreditamos, pois, que os métodos qualitativo e quantitativo são fundamentais à nossa pesquisa. Por um lado, preocupamo-nos em obter dados fidedignos e quantificáveis, considerando a grande envergadura do objeto de análise (Sistema UAB). Por outro, não desconsideramos a complexidade do fenômeno da pesquisa e a necessidade de inquirir qualitativamente as experiências dos entrevistados e seus elementos subjacentes. Portanto, a triangulação metodológica fez-se necessária na tentativa de atingir o objetivo proposto satisfatoriamente, por meio de dados quantitativos e qualitativos.

Quanto aos procedimentos metodológicos, primeiramente elaboramos um questionário virtual por meio do software Limesurvey. Trata-se de uma ferramenta digital que possibilita o desenvolvimento e o envio de questionários diretamente pelo sistema, a partir da criação de uma base com e-mails aos quais foram enviados os convites à pesquisa. Dessa forma, para construir a base de dados, utilizamos contatos de profissionais relacionados à EaD e ao Sistema UAB. Estes foram obtidos em fontes variadas, como: listas do Grupo Horizonte, participantes de eventos científicos da área, cursos e listas sobre EaD das quais participamos etc. Após a constituição da base de e-mails e os processos de filtragem, enviamos convites à pesquisa a exatamente 25.408 contatos que possivelmente atuam ou já atuaram no âmbito do Sistema UAB. Destes, 677 indicaram possuir experiência como docente neste Sistema e responderam a todas as perguntas do questionário virtual.

Posteriormente, realizamos entrevistas semiestruturadas com alguns profissionais que participaram da primeira etapa da pesquisa. Selecionamos os docentes com base em sua experiência na EaD e no âmbito do Sistema UAB. Ao todo, foram realizadas e transcritas 8 entrevistas. O perfil dos profissionais que participaram da nossa investigação se encontra a seguir, com o nome utilizado neste estudo em respeito ao sigilo dos participantes.

Quadro 1 - Nomenclatura utilizada no texto e perfil dos entrevistados

\begin{tabular}{|l|l|}
\hline Nomenclatura utilizada no texto & \multicolumn{1}{|c|}{ Experiência } \\
\hline Docente-formador/aplicador A & $\begin{array}{l}\text { Docente-autor/conteudista, docente-formador/aplicador e do- } \\
\text { cente-tutor virtual há mais de 5 anos. Doutor com formação na } \\
\text { área de Ciências Biológicas. Possui mais de 10 anos de experi- } \\
\text { ência na educação presencial. Atua como docente em universi- } \\
\text { dade federal com regime de dedicação exclusiva (40h). }\end{array}$ \\
\hline
\end{tabular}




\begin{tabular}{|c|c|}
\hline Docente-formadora/aplicadora B & $\begin{array}{l}\text { Docente-autora/conteudista e docente-formadora/aplicadora há } \\
\text { mais de } 5 \text { anos. Docente-tutora virtual há mais de } 7 \text { anos. Atua } \\
\text { como coordenadora pedagógica em curso a distância. Possui } \\
\text { mais de } 10 \text { anos de experiência na educação presencial. Mestre } \\
\text { na área de Ciências Humanas. Atua como docente em universi- } \\
\text { dade federal com regime de dedicação exclusiva ( } 40 \mathrm{~h}) \text {. }\end{array}$ \\
\hline Docente-formadora/aplicadora C & $\begin{array}{l}\text { Docente-autora/conteudista há mais de } 2 \text { anos. Docente-for- } \\
\text { madora/aplicadora e docente-tutora virtual há mais de } 3 \text { anos. } \\
\text { Possui mais de } 10 \text { anos de experiência na educação presencial. } \\
\text { Atuou como Coordenadora UAB. Doutora na área de Ciências } \\
\text { da Saúde. Atua como docente em universidade federal com re- } \\
\text { gime de dedicação exclusiva ( } 40 \mathrm{~h}) \text {. }\end{array}$ \\
\hline Docente-formador/aplicador D & $\begin{array}{l}\text { Docente-autor/conteudista há menos de } 1 \text { ano. Docente-forma- } \\
\text { dor/aplicador há mais de } 1 \text { ano. Possui mais de } 10 \text { anos de ex- } \\
\text { periência na educação presencial. Mestre na área de Ciências } \\
\text { Humanas. Atua como docente em universidade federal com re- } \\
\text { gime de dedicação exclusiva ( } 40 \mathrm{~h}) \text {. }\end{array}$ \\
\hline Docente-tutora virtual & $\begin{array}{l}\text { Docente-tutora virtual há mais de } 5 \text { anos. Possui pós-gradua- } \\
\text { ção lato sensu. Atualmente cursa mestrado na área de Ciências } \\
\text { Humanas. }\end{array}$ \\
\hline Docente-tutor presencial A & $\begin{array}{l}\text { Docente-autor/conteudista há mais de } 1 \text { ano. Docente-formador/ } \\
\text { aplicador há mais de } 3 \text { anos. Docente-tutor virtual há mais de } 5 \\
\text { anos. Docente-tutor presencial há mais de } 2 \text { anos. Possui mais } \\
\text { de } 3 \text { anos de experiência na educação presencial. Possui pós- } \\
\text {-graduação lato sensu. Atua como docente na Educação Básica. }\end{array}$ \\
\hline Docente-tutora presencial B & $\begin{array}{l}\text { Docente-tutora presencial há mais de } 7 \text { anos. Possui mais de } 10 \\
\text { anos de experiência na educação presencial. Possui pós-gradu- } \\
\text { ação lato sensu. Atua como docente na Educação Básica. }\end{array}$ \\
\hline Docente-tutora presencial C & $\begin{array}{l}\text { Docente-tutora presencial há mais de } 7 \text { anos. Possui mais de } 10 \\
\text { anos de experiência na educação presencial. Possui pós-gra- } \\
\text { duação lato sensu. Atua como coordenadora de Polo de Apoio } \\
\text { Presencial. }\end{array}$ \\
\hline
\end{tabular}

Fonte: Autoria própria.

\section{SOBRE AS RELAÇÕES DE HIERARQUIA NA EDUCAÇÃO A DISTÂNCIA}

Durante as investigações, foi de nosso interesse, a princípio, identificar como se constituem as relações hierárquicas no contexto do trabalho docente da EaD. Na medida em que as atividades se tornam interdependentes na polidocência, ocorre um processo de descentralização, isto é, as variadas funções deixam de ser estanques e diversos profissionais passam a trabalhar em conjunto para garantir a qualidade do processo de ensino-aprendizagem. Existe, portanto, um trabalho mais cooperativo, que vai à contramão da acentuada divisão proposta por modelos como o taylorismo-fordismo ${ }^{5}$. No entanto, em razão da existência de variados profissionais que devem atuar em consonância, a docência não deve prescindir de uma coordenação a fim de que seja garantida a eficácia do trabalho. Paradoxalmente, conjecturamos que existem

50 taylorismo é, grosso modo, a aplicação dos princípios da organização e do método científico aos trabaIhos de qualquer natureza. Já o fordismo diz respeito, em síntese, a um modelo de produção que procura evitar, ao máximo, o desperdício reduzindo, ao mínimo, o ciclo de transformações (CANTANHEDE, 1973). 
elementos que coadunam, ao mesmo tempo, com uma concepção de trabalho fragmentado mas também cooperativo ${ }^{6}$.

Assim, com vistas a desvelar a existência de um trabalho cooperativo, indagamos os participantes, nos questionários virtuais, sobre a dependência de suas atividades com relação às funções de outros profissionais. Os dados obtidos foram quantificados na Figura 1.

Figura 1 - Interdependência das atividades na EaD em relação às funções de outros profissionais.

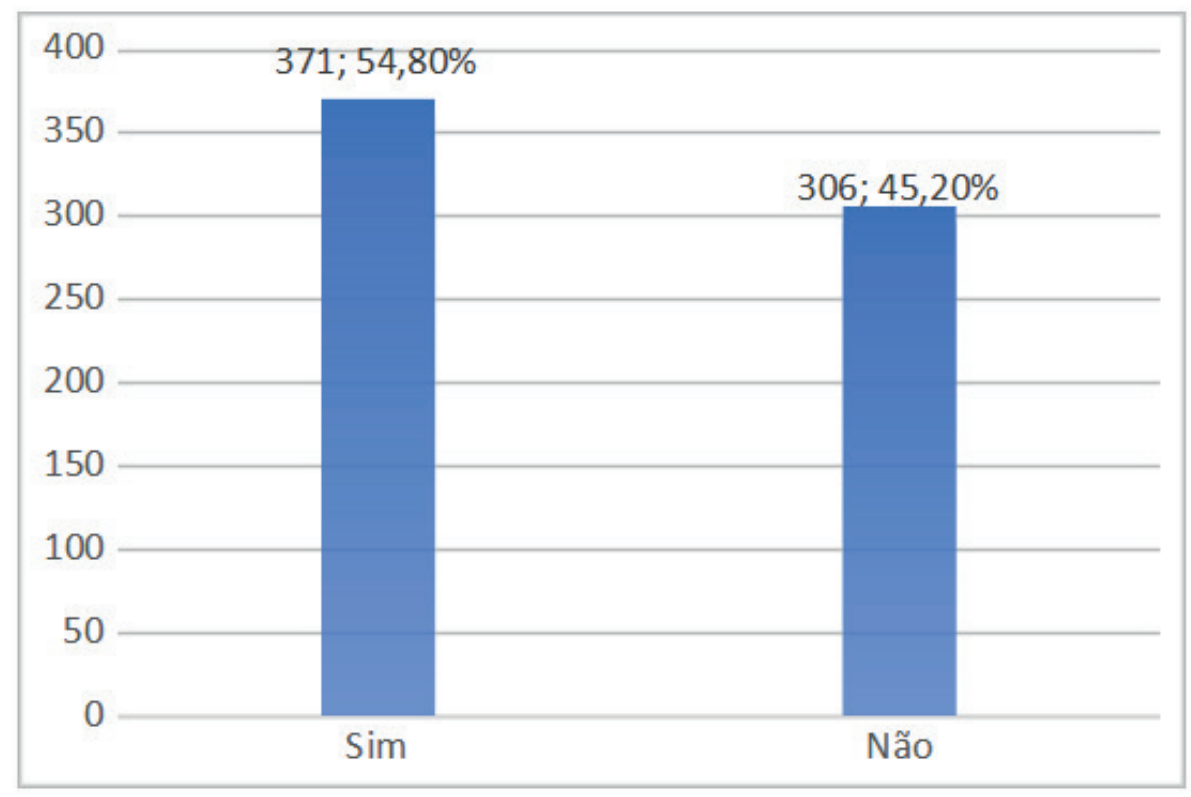

Fonte: Autoria própria.

De acordo com os dados, 306 docentes informaram que suas atividades não dependem e/ou afetam a função de outros profissionais da EaD. Em contrapartida, 371 participantes informaram existir essa dependência. Há, portanto, um número considerável de docentes que afetam ou são afetados pelas atividades de outros trabalhadores, dando indícios sobre a existência de um trabalho interdependente. Buscando validar a hipótese de uma atuação mais colaborativa, indagamos os 371 respondentes que disseram depender ou afetar o trabalho de outros profissionais da EaD, sobre o modo como ocorre essa dependência e quais são os profissionais envolvidos nesse processo. Algumas das respostas à questão foram sintetizadas no Quadro 2.

6 Entendemos que o trabalho fragmentado está mais relacionado à divisão acentuada, sem a interferência e a interdependência dos profissionais. Já o trabalho cooperativo compreende uma atuação menos estanque, cujas atividades de um trabalhador influenciam e/ou dependem diretamente das de outro, sem que isso implique, necessariamente, a inexistência da divisão das funções. 
Quadro 2 - Respostas referentes às formas como ocorrem a interdependência das atividades docentes na $\mathrm{EaD}$

\begin{tabular}{l}
\hline $\begin{array}{l}\text { Uma vez que trabalhamos em função de um currículo e de uma proposta formativa, existe interde- } \\
\text { pendência, embora aparentemente cada um funcione por si. }\end{array}$ \\
\hline Várias práticas que desenvolvo acabam sendo utilizadas por outros professores. \\
\hline $\begin{array}{l}\text { Vejo o trabalho na EaD muito pelo coletivo, então eu como professor recebo a colaboração de ou- } \\
\text { tros profissionais como técnicos de internet (aqui na Universidade) e as tutoras (nos polos), além } \\
\text { da coordenadora, esses são alguns exemplos. Não usei as palavras dependem/afetam por uma } \\
\text { questão de escolha discursiva, prefiro verbos mais flexíveis como colaborar. }\end{array}$ \\
\hline $\begin{array}{l}\text { Afetam diretamente os tutores, pois elaboramos as aulas para que eles possam ministrar nos } \\
\text { polos. }\end{array}$ \\
\hline $\begin{array}{l}\text { Atuando como tutora virtual, meu trabalho depende bastante do trabalho de outros profissionais, } \\
\text { como por exemplo da equipe técnica que estrutura a sala de aula virtual dentro do AVA, do profes- } \\
\text { sor que define os conteúdos da disciplina, inclusive elaborando um cronograma de qual assunto } \\
\text { será abordado em cada semana. }\end{array}$ \\
\hline Dependo totalmente do professor formador e coordenador do curso. \\
\hline Em alguns momentos dependo da parceria da coordenação e dos tutores dos cursos. \\
\hline $\begin{array}{l}\text { Enquanto tutor presencial, faço a interlocução entre os alunos e os professores e tutores a distân- } \\
\text { cia, facilitando a comunicação e contribuindo com os estudos em grupo. }\end{array}$ \\
\hline $\begin{array}{l}\text { O aluno, o professor-conteudista, a parte administrativa de EaD. Como professor-formador ou } \\
\text { tutor o nosso trabalho interfere diretamente no processo de ensino-aprendizagem do aluno e no } \\
\text { trabalho dos outros atores de EaD. }\end{array}$ \\
\hline $\begin{array}{l}\text { Os professores são os maiores dependentes. Nós que fornecemos as planilhas com as atividades } \\
\text { corrigidas, notas somadas e o resultado final. }\end{array}$ \\
\hline $\begin{array}{l}\text { Aqueles que dependem são os tutores das disciplinas. Aqueles que afetam são os níveis superio- } \\
\text { res: Coordenação Acadêmico-Pedagógica e Coordenação Tecnológica. Além disso, posso dizer } \\
\text { que os tutores também afetam, haja vista que estão diretamente em contato com os estudantes. } \\
\text { Também são responsáveis por manter a qualidade do curso. }\end{array}$ \\
\hline
\end{tabular}

Fonte: Autoria própria.

As respostas dos docentes nos permitem depreender informações relacionadas à existência de um trabalho mais cooperativo. Contudo, também constatamos a existência de uma divisão mais acentuada entre concepção e execução, como a resposta na qual um docente informou preparar aulas que serão ministradas pelos tutores nos polos. Constituindo um paradoxo, o trabalho docente na EaD parece estar permeado por elementos que compõem uma divisão do trabalho mais rigorosa, enquanto existe, concomitantemente, um trabalho cooperativo e interdependente. Nas palavras de Belloni (2003), ainda que a divisão do trabalho docente possa evoluir a um modelo menos centralizado, automatizado, hierarquizado e muito especializado, essa evolução provável não modifica fundamentalmente a característica principal da EaD, que é "a transformação do professor de uma entidade individual em uma entidade coletiva" (BELLONI, 2003, p. 81).

De fato, ao retomarmos tal temática durante as entrevistas realizadas com docentes, reiteramos a existência de um trabalho mais colaborativo. Inclusive, uma docente-forma- 
dora/aplicadora informou que, na universidade na qual atua, há uma iniciativa para que os docentes-tutores virtuais sejam ouvidos e participem do processo de estruturação e elaboração das disciplinas. Essa profissional entrevistada afirma que, dada a importância dos docentes-tutores ao processo de ensino-aprendizagem, bem como sua proximidade com os discentes, é de fundamental importância que suas experiências sejam consideradas nas etapas de confecção do material didático e de elaboração das atividades no ambiente virtual. De acordo a docente entrevistada:

[...] então agora a gente tá fazendo uma tentativa, vamos chamar todo mundo antes [os docentes-tutores virtuais] [...] a gente conversou com os tutores, eles preferem fazer assim, né, então a gente tem convidado antes [da aplicação da disciplina], né, um convite, fala: "você vem participar junto". No meu caso, quando eu assumi a disciplina de Libras do curso de Filosofia aqui, eu fiz assim com os meus tutores [...] eu falei: "esse, esse e esse, senta comigo aqui, isso que eu pensei [para a confecção da disciplina], o que que vocês acham?" Ficou muito melhor do que eu tava pensando, porque a gente chega com uma proposta, mas "ah não, isso aqui não deu certo, vamos trocar isso". E aí a gente vai construindo junto [docente-formador/aplicador junto com docentes-tutores virtuais] (docente-formadora/aplicadora B).

No bojo de um trabalho mais cooperativo, encontram-se também outras questões complexas que incorrem em tensões no relacionamento entre os profissionais. Sob o entendimento de Mill e Fidalgo (2002), o trabalho coletivo, uma vez que implica em uma interdependência entre as atividades de diferentes trabalhadores dos cursos oferecidos pela EaD, afeta as relações entre os trabalhadores do grupo. Para esses autores, o fato de a qualidade do trabalho de um trabalhador ou de o mérito deste não depender apenas de sua capacidade ou competência leva-o a desenvolver certo interesse pela qualidade do trabalho de um colega de equipe, o que acaba influenciando o modo como esse profissional se relacionará com o outro trabalhador da equipe (MILL; FIDALGO, 2002).

Buscando, pois, compreender essas relações entre os profissionais docentes na EaD, questionamentos os participantes sobre a qualidade dos relacionamentos estabelecidos com outros profissionais no contexto da polidocência. Procuramos identificar a percepção dos docentes no que respeita à relação com os pares e outros agentes envolvidos no processo de trabalho. As informações obtidas estão presentes na Tabela 1.

Tabela 1 - Qualidade do relacionamento entre os docentes e demais profissionais no contexto da polidocência

\begin{tabular}{|l|c|c|c|c|c|}
\hline $\begin{array}{c}\text { Qualidade do relacionamen- } \\
\text { to com cada profissional } \\
\text { docente }\end{array}$ & Péssimo & Ruim & $\begin{array}{c}\text { Não se } \\
\text { aplica }\end{array}$ & Bom & Ótimo \\
\hline Docente-autor/conteudista & $4(0,59 \%)$ & $\begin{array}{c}10 \\
(1,48 \%)\end{array}$ & $\begin{array}{c}188 \\
(27,77 \%)\end{array}$ & $\begin{array}{c}254 \\
(37,52 \%)\end{array}$ & $\begin{array}{c}221 \\
(32,64 \%)\end{array}$ \\
\hline Docente-formador/aplicador & $1(0,15 \%)$ & $\begin{array}{c}13 \\
(1,92 \%)\end{array}$ & $\begin{array}{c}121 \\
(17,88 \%)\end{array}$ & $\begin{array}{c}282 \\
(41,65 \%)\end{array}$ & $\begin{array}{c}260 \\
(38,40 \%)\end{array}$ \\
\hline
\end{tabular}




\begin{tabular}{|l|c|c|c|c|c|}
\hline Docentes-tutores virtuais & $1(0,15 \%)$ & $\begin{array}{c}13 \\
(1,92 \%)\end{array}$ & $32(4,73 \%)$ & $\begin{array}{c}309 \\
(45,64 \%)\end{array}$ & $\begin{array}{c}322 \\
(47,56 \%)\end{array}$ \\
\hline Docentes-tutores presenciais & $5(0,74 \%)$ & $\begin{array}{c}21 \\
(3,10 \%)\end{array}$ & $59(8,71 \%)$ & $\begin{array}{c}294 \\
(43,43 \%)\end{array}$ & $\begin{array}{c}298 \\
(44,02 \%)\end{array}$ \\
\hline Equipe de suporte pedagógico & $5(0,74 \%)$ & $\begin{array}{c}22 \\
(3,25 \%)\end{array}$ & $70(10,34 \%)$ & $\begin{array}{c}303 \\
(44,76 \%)\end{array}$ & $\begin{array}{c}277 \\
(40,91 \%)\end{array}$ \\
\hline Equipe de suporte técnico & $4(0,59 \%)$ & $\begin{array}{c}31 \\
(4,58 \%)\end{array}$ & $44(6,50 \%)$ & $\begin{array}{c}330 \\
(48,74 \%)\end{array}$ & $\begin{array}{c}268 \\
(39,59 \%)\end{array}$ \\
\hline $\begin{array}{l}\text { Equipe de suporte administra- } \\
\text { tivo }\end{array}$ & $8(1,18 \%)$ & $\begin{array}{c}24 \\
(3,54 \%)\end{array}$ & $36(5,32 \%)$ & $\begin{array}{c}337 \\
(49,78 \%)\end{array}$ & $\begin{array}{c}272 \\
(40,18 \%)\end{array}$ \\
\hline
\end{tabular}

Fonte: Autoria própria.

A análise dos dados ilustra que a maior parte dos respondentes disse ter um bom/ ótimo relacionamento com os outros profissionais envolvidos no trabalho na EaD. Aliás, a porcentagem de participantes que afirmou ter uma relação que varia entre ruim e péssima é ínfima. Isso significa que aparentemente os profissionais lidam bem com o trabalho em grupo exercido no contexto da polidocência - quando ele existe. A fim de validar essa asserção, perguntamos aos docentes quais as vantagens e desvantagens no que tange ao trabalho em equipe. Algumas das respostas mais pertinentes à nossa pesquisa foram sintetizadas no Quadro 3.

Quadro 3 - Percepção dos docentes sobre possíveis vantagens e/ou desvantagens do trabalho em grupo no contexto da polidocência

Oportunidade para compartilhar informações e conhecimentos.

A participação de todos!

A atuação em grupo, em particular com os tutores, contribui com novos olhares para a disciplina e é fundamental no aumento da interação com os discentes.

As principais vantagens são as discussões e deliberações coletivas. A principal desvantagem refere-se a não sabermos lidar com essas discussões coletivas e, muitas vezes, não chegarmos ao consenso e, portanto, atrasamos e/ou impedimos que o processo pedagógico/administrativo ocorra em um fluxo contínuo e de avaliação contínua.

Vantagens: multiplicidade de ideias. Desvantagens: o trabalho fica descoordenado.

Para mim o trabalho em grupo é muito vantajoso, pois podemos compartilhar ações, solicitar ajuda.

O trabalho em grupo possibilita a discussão de temas e levantamento de possíveis soluções, além da uniformidade de ações.

Fonte: Autoria própria.

As respostas dos docentes dão, novamente, indícios de uma interdependência entre as atividades, sugerindo um trabalho mais colaborativo. Além disso, essa mesma atuação coletiva pode implicar em empecilhos ao processo de ensino-aprendizagem. Em uma das respostas, um docente afirmou que as discussões e deliberações coletivas dificultam um consenso. Houve outro participante que disse haver um trabalho descoordenado em razão das atividades em grupo. É 
preciso, portanto, que as funções exercidas no contexto da polidocência sejam bem organizadas. Para Kenski (2013), no trabalho docente da EaD a interação entre todos é fundamental para que o processo desencadeado seja compreendido por todos e para que os feedbacks dos alunos sejam informados e repliquem em ajustes e redefinições de acordo com os encaminhamentos propostos. Desse modo, o trabalho docente na modalidade não deve prescindir de uma coordenação e de uma organização com vistas à garantia de qualidade no processo de ensino-aprendizagem. É por isso que, independentemente de um trabalho mais colaborativo, encontram-se relações de hierarquia no seio do trabalho polidocente.

Ainda buscando identificar a existência de uma gestão menos centralizada e mais participativa, questionamentos os respondentes sobre a percepção de autonomia em suas atividades. Interessou-nos compreender se nesse trabalho coletivo os docentes identificam-se autônomos durante o exercício de suas funções. As respostas obtidas foram quantificadas na Figura 2.

Figura 2 - Percepção dos docentes em relação à autonomia no exercício de suas atividades na EaD.

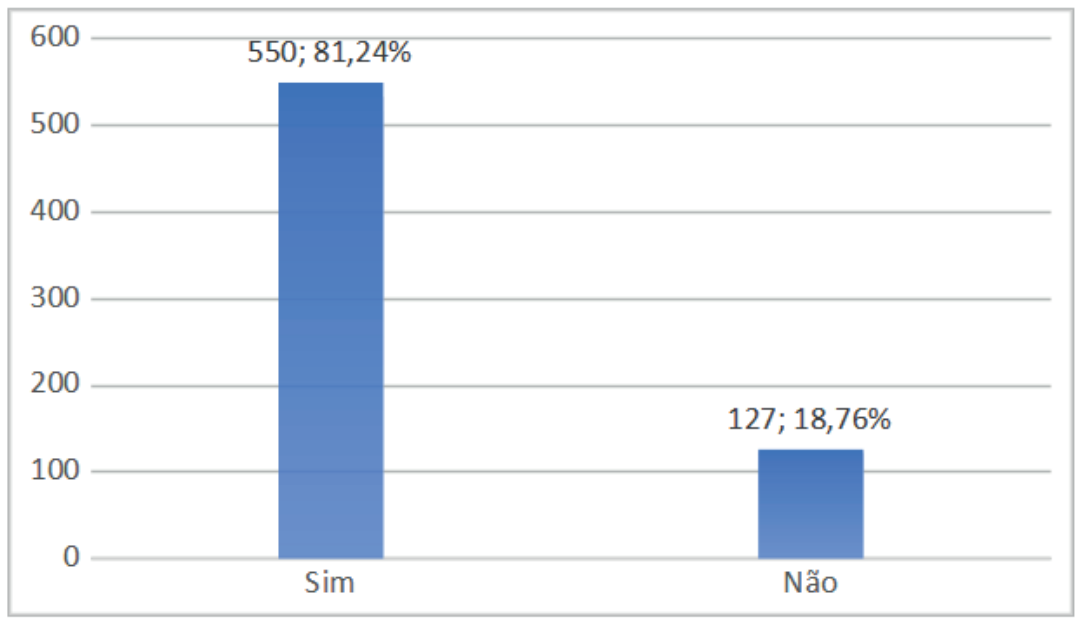

Fonte: Autoria própria.

Aparentemente os profissionais gozam de autonomia em suas atividades. Isso foi confirmado por meio das respostas aos questionários virtuais, nas quais 550 docentes afirmam se sentir autônomos no exercício de suas funções. Essa análise é importante, desvelando que, ainda que as atividades sejam interdependentes, há certa responsabilização pelo trabalho. Essa autonomia sobre as atividades parece ir à contramão de algumas das críticas concebidas à gestão participativa ${ }^{7}$. De acordo com Cattani (1997), alguns críticos dessa nova forma de gestão afirmam que, em determinadas experiências, existe um núcleo estável de trabalhadores rodeados por subcontratados ou assalariados de forma precária. Os primeiros podem intervir no processo produtivo, enquanto os demais não têm direito às vantagens 
decorrentes do novo modelo organizacional (CATTANI, 1997). Todavia, embora os docentes-tutores virtuais, por exemplo, possuam uma situação mais precária quanto à contratação se comparados aos docentes-formadores/aplicadores ${ }^{8}$, em nossa investigação constatamos que vários deles afirmam também participar - ou ao menos serem ouvidos - no processo de modificação e estruturação da disciplina. Obviamente, existem limitações no que respeita a essa interferência nas decisões e nas posturas do docente-formador/aplicador, mas os docentes-tutores virtuais parecem não estar, por regra, apartados dos demais processos de trabalho e, geralmente, suas opiniões são ouvidas e, se pertinentes, consideradas.

Contudo, no que toca aos docentes-tutores presenciais, nossas análises, mormente durante as entrevistas, não se mostraram tão animadoras. Estando estes profissionais mais distantes da universidade, parece-nos que sua participação nas etapas de elaboração, estruturação e modificação das disciplinas é, em algumas experiências, consideravelmente reduzida se comparada a dos docentes-tutores virtuais. Mesmo que esses docentes tenham liberdade para expressar sua opinião, por vezes suas considerações não obtêm resultados. Algumas das falas dos entrevistados que concernem a essa perspectiva foram sintetizadas abaixo:

Mas eu não tinha tanta autonomia, porque eu tinha.... é... colocar pra eles [os alunos] um caminho, eu tinha que sugerir um caminho [de aprendizagem], que eu... às vezes eu não poderia ajudar, e às vezes mesmo que eu tivesse domínio daquele conteúdo [...] como tutora presencial, eu não poderia interferir [...]. É... o que eu sinto mesmo, acho que eu vou cair nessa parte, que você falou da autonomia. Porque é essa questão de a gente não conseguir evitar evasão [...]. Essa foi a primeira vez que um coordenador me deu uma resposta, porque igual, o outro curso em que eu atuava $^{9}$, eu lembro que quando eu sugeria [mudanças no ambiente virtual/material didático], eu ficava preocupada até no texto que eu ia escrever pra enviar, como que eu ia ser recebida, como que ia ser lido, mas eles nunca me retornaram. Esse [o atual curso em que atua], a semana passada mesmo quando eu mandei, ele já me colocou [respondeu], até já dei retorno pra aluna (docente-tutora presencial B).

Como eu vou te dizer isso aí? Tinha a possibilidade, né, o espaço pra opinar, mas uma coisa é você dar o palpite, outra coisa é ver o seu pitaco aparecer, né. [...] teve um conteúdo onde apareceu lá um deus aristotélico com "D" maiúsculo, e aí a gente foi questionar o fato do cara estar escrevendo 400 anos antes de cristo [...] e aí nós

trabalho, nos procedimentos administrativos e comerciais e, com menor frequência, na condução geral da empresa ou da instituição.

8 Em nossa pesquisa identificamos que $75,36 \%$ dos docentes-tutores virtuais e $86,57 \%$ dos docentes-tutores presenciais não possuem vínculo empregatício para com a universidade. Em relação aos demais educadores, somente $28 \%$ dos docentes-autores/conteudistas e $27,91 \%$ dos docentes-formadores/aplicadores não possuem vínculo empregatício. Salientamos que esses dados foram calculados com base naqueles profissionais que afirmaram possuir experiência em apenas cada uma das funções, desconsiderando, portanto, aqueles que atuam ou já atuaram em mais de um perfil docente no âmbito do Sistema UAB. Essa filtragem dos dados se mostrou necessária a fim de obter uma amostra mais fidedigna do vínculo de cada profissional docente.

9 Optamos por não inserir o nome do curso a fim de manter o sigilo da entrevistada. 
consultamos primeiro a professora responsável pelo material. Ela não tava acessível, porque tava num congresso, tava fora, e aí nós acessamos a coordenadora do curso, e aí nós levantamos a lebre, né, falar de um deus, 400 anos antes de cristo vir aqui, só se fossem uns deuses gregos, né. Tava no contexto de Aristóteles, mas não era isso que o material deixava explícito, e aí o nosso questionamento, a nossa sugestão foi ouvida com certeza ${ }^{10}$ [ironia]. Não [modificaram o material]! (docente-tutor presencial A).

As falas supramencionadas permitem-nos observar que, aparentemente, os docentes-tutores presenciais ficam à margem de decisões relacionadas à elaboração, estruturação e modificação do material didático. No entanto, nas respostas dos questionários virtuais, curiosamente não identificamos uma correlação entre os docentes-tutores presenciais e os entrevistados que afirmaram não possuir autonomia no exercício de suas funções na EaD. Por isso, baseando-nos em nossas análises - nos questionários virtuais e nas entrevistas presumimos que a existência de uma gestão mais participativa e de relações hierárquicas menos acentuadas se relaciona diretamente à experiência de cada instituição. Enquanto algumas universidades parecem se preocupar com uma gestão mais democrática, outras adotam posturas que acabam contribuindo para a alienação dos trabalhadores. É o caso, por exemplo, das instituições que restringem as atividades dos docentes-tutores presenciais a funções mais generalistas, sem que estes possam opinar/interferir no conteúdo ${ }^{11}$.

A despeito das especificidades de cada experiência de EaD interferirem diretamente no processo de trabalho, identificamos, em praticamente todas as análises, a existência de relações hierárquicas no contexto da polidocência. Durante as entrevistas, os docentes informaram que essa hierarquia é bastante nítida e que, geralmente, no contexto da aplicação da disciplina, o docente-formador/aplicador é o responsável por coordenar as atividades dos docentes-tutores (virtuais e presenciais). Mesmo que exista, em algumas experiências, certa liberdade para que os docentes-tutores interfiram no processo de ensino-aprendizagem, há certas limitações e, normalmente, quaisquer mudanças mais estruturais requerem a aprovação dos docentes-formadores/aplicadores. Já em relação a estes, identificamos que no interior das universidades também existe uma hierarquia nítida, tal como é na educação presencial. Desse modo, ainda que os profissionais tenham autonomia para conduzir suas turmas, suas ações devem estar harmonizadas aos interesses da instituição e da coordenação do curso. Em nossa investigação constatamos, inclusive, que os profissionais parecem lidar bem e, via de regra, consideram importante a existência de certas hierarquias às atividades, considerando-se que, por ser sobremaneira complexo, o trabalho docente na EaD exige coordenação.

10 O docente-tutor presencial foi enfático ao usar da ironia para afirmar que o material didático não foi modificado.

11 Nestas páginas, restringimo-nos a considerar que existem experiências de EaD nas quais há uma alienação do docente-tutor presencial em relação ao conteúdo das disciplinas. Porém, não empreenderemos uma análise sobre as implicações pedagógicas dessa postura adotada por algumas universidades. Evidentemente, existem aspectos que subjazem e, de certa forma, justificam esse posicionamento, mas isso é assunto para outros estudos. 


\section{SOBRE OS SABERES E CONHECIMENTOS DOCENTES NA EDUCAÇÃO A DISTÂNCIA}

Posteriormente às considerações e resultados de nosso estudo a respeito das relações de hierarquia na EaD, outra discussão se faz pertinente acerca do trabalho dividido e fragmentado da modalidade. Trata-se dos saberes e conhecimentos utilizados no contexto do trabalho polidocente e suas implicações às relações de poder. Nas palavras de Mill e Fidalgo (2004), sob pena de estar incompleta, a análise do processo de trabalho deve levar em conta os saberes detidos pelo grupo de trabalhadores envolvidos em certo conjunto de atividades; isto é, cabe analisar quais são os saberes mobilizados pelos trabalhadores para o desenvolvimento de certo trabalho. Segundo esses autores, além das relações de saber, é preciso compreender o processo de trabalho em sua totalidade, considerando também e conjuntamente as formas de gestão dos processos de trabalho, o modo como ele se organiza e as relações travadas entre os trabalhadores (MILL; FIDALGO, 2004).

Posto isso, interessa-nos, nestas páginas, compreender as relações de saber e poder presentes no trabalho docente da EaD. Neste artigo, inferimos que existem relações hierárquicas nessa modalidade. Nomeadamente, os docentes-formadores/aplicadores são os responsáveis por coordenar as atividades dos docentes-tutores (presenciais e virtuais). Conquanto tenham participação, por vezes, em etapas importantes do processo de elaboração e modificação do material didático e dos conteúdos das disciplinas, as funções dos docentes-tutores estão subordinadas às dos docentes-formadores/aplicadores - em algumas circunstâncias, também às dos docentes-autores/conteudistas. Entendemos, portanto, que na organização do trabalho docente da EaD se encontram relações de poder.

Para Dias (2008), um dos mais importantes processos sociais refere-se à capacidade que possuem os indivíduos, entre os quais as organizações, de modificarem o comportamento de outros grupos ou pessoas. Esse processo, fundamental aos seres humanos, denomina-se poder. Este ocorre em todas as relações sociais, disseminando-se em todas as sociedades e grupos sociais. Trata-se, na verdade, de um meio, que o grupo ou indivíduo possui, de fazer com que "coisas" sejam realizadas por outros indivíduos ou grupos (DIAS, 2008). Por isso que:

[...] o poder deve ser analisado como algo que funciona em cadeia, não está localizado aqui ou ali, nem está nas mãos de alguns. O poder não é um bem, mas é algo que se exerce em rede, e nessa rede todos os indivíduos circulam, sendo que qualquer um pode estar em posição de ser submetido ao poder, mas também exercê-lo. Nessa perspectiva, não se treta da questão de "quem está no poder", mas de estudá-lo no ponto em que se implanta e produz seus efeitos reais (PRATA, 2005, p. 109, grifo nosso). 
Por sua vez, entendemos que as relações de poder têm que ver com as de saber. Pois os mecanismos de poder e saber funcionam não apenas em escolas ou relações pedagógicas, mas em todo o âmbito social, sendo promovidas e aceitas com naturalidade pela sociedade (MATTEI, 2008). Pode-se afirmar que a hierarquização de saberes e poder ainda hoje separa sujeitos, classificando-os e ordenando-os em classes sociais, em lugares específicos, em trabalhos, em escolas etc. (MATTEI, 2008). Na EaD, essa hierarquização nos parece bastante nítida, porque os sujeitos são discriminados em diferentes perfis docentes que possuem maior ou menor poder dentro do contexto da polidocência. Por isso, supomos que há uma relação entre poder e saber. Haja vista a existência de profissionais com formações diversas e, por consequência, conhecimentos e saberes distintos, é provável que exista uma relação entre esses aspectos e a hierarquia constituída no bojo da EaD. Propomos, portanto, essa discussão a seguir.

\section{SOBRE AS RELAÇÕES DE SABER E PODER NA EDUCAÇÃO A DISTÂNCIA}

Para Mattei (2008), historicamente o ensino constitui uma hierarquia de saberes e poderes, no qual o professor é o detentor do saber. Segundo essa autora, atualmente, ainda que existam resquícios dessa relação vertical entre docentes e discentes, o professor passou a ser o mediador do ensino que, por sua vez, tornou-se mais democrático. Mas a hierarquização de saberes e poder ainda hoje separa os sujeitos, classificando-os (MATTEI, 2008). Sob o entendimento de Dias (2008), existem inúmeros elementos que podem se constituir em fonte de poder, sendo a posse de conhecimentos como dos mais importantes. Entretanto, a posse pura e simples do conhecimento não significa poder. Somente por meio da habilidade de manipulação desse conhecimento é que o indivíduo poderá transformá-lo em fonte efetiva de dominação de outrem (DIAS, 2008).

No contexto do trabalho polidocente encontram-se relações hierárquicas. Por praxe, o docente-formador/aplicador é quem coordena as atividades dos docentes-tutores (presenciais e virtuais). Noutras palavras, as atividades destes estão subordinadas às funções daquele. Mesmo que a polidocência apresente, por vezes, um trabalho mais colaborativo e uma gestão menos centralizada, as hierarquias se mostram presentes na EaD. Nossa hipótese é a de que, para além da maneira como o Sistema UAB tem se configurado - que acaba por endossar as relações hierárquicas -, os saberes e conhecimentos detidos por cada profissional têm influência nas relações de poder da EaD.

Colimando ratificar nossas proposições, correlacionamos, nos questionários virtuais, a experiência em cada um dos perfis docentes e a respectiva titulação dos profissionais. Foi de nosso interesse observar alguma relação entre o título dos trabalhadores e as funções na EaD. O resultado dessa análise está presente na Tabela 2. 
Tabela 2 - Titulação dos profissionais e experiência docente na EaD ${ }^{12}$

\begin{tabular}{|l|c|c|}
\hline $\begin{array}{c}\text { Titulação dos } \\
\text { docentes }\end{array}$ & $\begin{array}{c}\text { Possuem experiência como } \\
\text { docente-tutor virtual e/ou pre- } \\
\text { sencial }\end{array}$ & $\begin{array}{c}\text { Possuem experiência como docente-au- } \\
\text { tor/conteudista e/ou docente-formadorl } \\
\text { aplicador }\end{array}$ \\
\hline Doutor (231) & $113(48,92 \%)$ & $195(84,42 \%)^{*}$ \\
\hline Mestre (202) & $158(78,22 \%)$ & $129(63,86 \%)$ \\
\hline $\begin{array}{l}\text { Especialista e/ou } \\
\text { Graduado (244) }\end{array}$ & $235(96,31 \%)$ & $71(29,10 \%)$ \\
\hline
\end{tabular}

* No Capítulo 4 identificamos que o salário ou valor da bolsa é a maior causa de insatisfação dos docentes para com o trabalho na EaD. Todavia, 30\% dos docentes-tutores (presenciais e/ou virtuais) que não possuem pós-graduação stricto sensu optaram pelo trabalho nessa modalidade devido à remuneração. Talvez, profissionais com menor titulação sejam mais propensos a se contentar com salários mais baixos e condições de trabalho mais precárias. Nossos dados não nos permitem estabelecer análises acertadas quanto a isso, mas, certamente, novos estudos sob essa perspectiva são necessários e pertinentes às pesquisas sobre a EaD.

Fonte: Autoria própria.

Nossa pesquisa evidencia que a quantidade de doutores que atuam ou já atuaram como docentes-autores/conteudistas e/ou docente-formadores/aplicadores é consideravelmente maior que a de mestres, graduados ou especialistas. Ora, não desconsideramos que, no âmbito do Sistema UAB, os profissionais que atuam nessas funções são, via de regra, docentes da instituição que passam a desenvolver atividades na EaD. Logo, é compreensível que o número de doutores atuando como autores/ conteudistas e/ou formadores/aplicadores seja maior, o que é profícuo à modalidade na medida em que profissionais mais qualificados são responsáveis pela elaboração do conteúdo e, de certa forma, pela condução e coordenação do processo de ensino-aprendizagem. Mas os nossos dados também elucidam que parte considerável dos docentes-tutores (virtuais e presenciais) não possui pós-graduação stricto sensu.

Nesse sentido, acreditamos que a tutoria seja, muitas vezes, um caminho que profissionais com menor titulação encontram para adquirir saberes e conhecimentos advindos da experiência no ensino superior e na EaD. Isso ficou evidente a partir dos dados da Tabela 3, referentes aos 235 profissionais que atuam ou já atuaram como docentes-tutores (presenciais e/ou virtuais) e que são somente graduados ou especialistas.

12 As somas das porcentagens não resultam em 100\%, porque vários profissionais possuem experiência em mais de um perfil docente. Além disso, o número entre parênteses, à frente da titulação, na coluna da esquerda, diz respeito ao total de respondentes que possuem doutorado, mestrado, especialização (lato sensu) ou apenas graduação, respectivamente. 
Tabela 3 - Principais motivações para atuar na EaD ${ }^{13}$

\begin{tabular}{|l|c|}
\hline \multicolumn{2}{|c|}{ Principais motivos para atuar na EaD } \\
\hline Remuneração & $87(37,02 \%)^{1}$ \\
\hline Experiência em atuar na EaD & $173(73,62 \%)$ \\
\hline Experiência em atuar no nível superior & $108(45,96 \%)$ \\
\hline Experiência em atuar como docente & $58(24,68 \%)$ \\
\hline Ausência de oportunidades de trabalho & $10(4,26 \%)$ \\
\hline Enriquecimento do currículo de forma geral & $139(58,15 \%)$ \\
\hline Oportunidade de atuar em uma IPES & $117(49,79 \%)$ \\
\hline
\end{tabular}

Fonte: Autoria própria.

As informações acima permitem-nos observar que 87 respondentes, isto é, $73,62 \%$ dos profissionais que atuam ou já atuaram como docentes-tutores (virtuais e/ou presenciais) e que são graduados ou especialistas, optaram pelo trabalho na EaD em razão da experiência. Quer dizer que, para esses trabalhadores, os saberes e conhecimentos provenientes da prática profissional constituem-se como o principal motivo para atuar na tutoria. Também se destacaram outras motivações voltadas à experiência, quer como docente no nível superior, quer como profissional de uma Instituição Pública de Ensino Superior (IPES). Ademais, 139 respondentes, ou $58,15 \%$ do total, afirmaram que a tutoria e as atividades na EaD são, na verdade, uma maneira de enriquecimento do currículo.

Destarte, os docentes-tutores (virtuais e presenciais) encontram na EaD uma via para atuar no ensino superior, adquirir experiência na modalidade, enriquecer o currículo etc., ainda que não possuam título de mestre e/ou doutor. Em nossa investigação, observamos que os editais para seleção de tutores, geralmente, não exigem que o candidato possua pós-graduação stricto sensu - embora a titulação seja considerada no processo seletivo. Na condição de "aprendizes" e, muitas vezes, sem título de mestre e/ou doutor, supomos que os docentes-tutores, além de estarem sujeitos às precariedades de sua função, parecem se adaptar mais facilmente às relações hierárquicas que se constituem no cerne da polidocência, isto é, do trabalho docente realizado no âmbito do Sistema UAB.

Numa das entrevistas realizadas com um docente-tutor presencial, identificamos que esse trabalhador compreende suas atividades num plano inferior ao dos docentesformadores/aplicadores. Para ele, o fato de não possuir uma pós-graduação stricto sensu o coloca apenas numa posição ligeiramente superior à dos alunos, que logo tornar-se-ão graduados, tal como ele. Além disso, identificamos nas entrevistas com outros docentes-

13 A soma das respostas não equivale aos 235 respondentes, pois a questão permitia que fosse assinalada mais de uma opção. 
tutores, que os saberes e conhecimentos oriundos da formação continuada, sobretudo da pós-graduação stricto sensu, consolidam os docentes-formadores/aplicadores em sua posição hierarquicamente superior. Parece-nos que, para alguns trabalhadores, é compreensível que suas atividades sejam coordenadas por um mestre ou um doutor, visto que os saberes e conhecimentos formais, corroborados por certificação, possuem maior validade no contexto da polidocência. Significa, pois, que a sabedoria proveniente da prática profissional, por exemplo, situa-se num plano inferior nas relações de poder.

Segundo Deleuze (1992 apud PRATA, 2005), o modelo de sociedade disciplinar pode ser questionado na contemporaneidade, pois os meios de confinamento, como a prisão, o hospital, a fábrica, a família e a escola, encontram-se numa crise generalizada. Nas sociedades ditas disciplinares, o indivíduo passava constantemente de um espaço fechado a outro, cada um com suas leis (primeiro a família, depois a escola, depois a fábrica etc.) (PRATA, 2005). Hoje, o poder seria cada vez mais ilocalizável, porque está disseminado entre os nós das redes ${ }^{14}$ (COSTA, 2004). Ele se move com a velocidade do sinal eletrônico e tornou-se verdadeiramente extraterritorial, não mais limitado pela resistência do espaço (PRATA, 2005). Nessa ambiência, a crise das sociedades disciplinares significa, noutras palavras, que os cercados que costumavam definir o espaço limitado das instituições foram derrubados, de modo que a lógica que funcionava dentro das paredes institucionais agora se espalha por todo terreno social, à medida que interior e exterior estão se tornando impossíveis de distinguir (DELEUZE, 1992 apud PRATA, 2005).

Tais considerações concernem às especificidades que perpassam as propostas de EaD na contemporaneidade ${ }^{15}$. Posto que o espaço físico das instituições não mais delimita as atividades que permeiam o processo de ensino-aprendizagem, recorre-se a novos mecanismos de controle e a novas formas de se estabelecer relações de poder no bojo das organizações. O Sistema UAB, na forma como foi constituído, parece fomentar relações hierárquicas que transcendem aquelas estabelecidas no seio institucional. Tendo em vista

14 De acordo com Costa (2004), nas sociedades disciplinares, preocupava-se com o movimento físico dos indivíduos, seu deslocamento espacial. Em contrapartida, nas sociedades de controle a preocupação se direciona à vigilância das mensagens, ao trânsito de comunicações. Em nossa pesquisa, identificamos, sobretudo nas entrevistas, que há uma preocupação, no Sistema UAB, de que as interações entre docentes-tutores e discentes aconteçam no ambiente virtual, para que a troca de mensagens fique sempre registrada. Talvez seja esse um indício da preocupação atinente às sociedades de controle, que valorizam mais o domínio sobre o fluxo das informações, em vez do interesse pela movimentação espacial.

15 Nas sociedades de controle, em que o poder se mostra disseminado e difuso, a dominação se baseia no delineamento do perfil dos indivíduos. Preocupa-se com o fluxo de informações, com os padrões de comportamento. O poder não mais acontece de forma vertical, mas horizontal e impessoal (COSTA, 2004). Contudo, parece-nos que, na EaD desenvolvida no âmbito do Sistema UAB, ainda existem relações hierárquicas e de poder calcadas nas sociedades disciplinares, nas quais há uma figura que preenche o lugar do poder (COSTA, 2004), personificada pela figura de um docente-formador/aplicador. Mas acreditamos que o Sistema UAB também recorre a outras formas de controle concernentes ao desenvolvimento das tecnologias, numa dominação que não mais se limita ao espaço físico e que não prima pelo controle espacial dos sujeitos. $\mathrm{A}$ lógica que funcionava dentro das instituições se torna, portanto, extraterritorial. Certamente, são proposições iniciais, que precisam ser aprofundadas à luz das mudanças nas relações de poder provenientes da contemporaneidade. 
que os profissionais atuam para além dos limites da universidade - de sua residência, dos Polos de Apoio Presencial ou, em tempos de ubiquidade, de quaisquer lugares com acesso à Internet ${ }^{16}$ - engendram-se novas formas de dominação. Acreditamos que a tutoria no Sistema UAB, assentando-se nas relações de saber que acabam sendo indissociáveis às de poder, assegura que as atividades dos docentes-tutores sejam coordenadas por outros profissionais formalmente mais qualificados no contexto da polidocência. Para tanto, a seleção de trabalhadores que anseiam por experiência profissional e que possuem menor titulação constitui-se como meio para consolidar as relações hierárquicas presentes na EaD e consideradas importantes ao trabalho coletivo - inclusive para os próprios docentes, como verificado em nossa pesquisa.

À guisa de exemplo, constatamos, em uma entrevista realizada com uma docente-tutora presencial, que o controle de suas atividades se estabelecia mediante a sua qualificação profissional. Nos cursos em que atuou, a universidade adotava a postura de não permitir a interferência da tutoria presencial quanto às dúvidas do conteúdo. Dada a dificuldade em monitorar todas as atividades dos docentes-tutores presenciais que atuam distantes da universidade, os conhecimentos e saberes oriundos da formação continuada eram responsáveis por delimitar as funções desses trabalhadores. Dito noutras palavras, se os problemas eram atinentes ao conteúdo e aos materiais didáticos, o docente-tutor presencial deveria imediatamente direcioná-los aos docentes-formadores/aplicadores que, como mestres e/ou doutores, possuíam, em tese, competência para resolvê-los.

Outro aspecto observado em nossa pesquisa diz respeito aos docentes-tutores (virtuais e, sobretudo, presenciais) que acabam utilizando mais os saberes e conhecimentos relacionados ao trabalho em equipe do que os demais trabalhadores no contexto da polidocência ${ }^{17}$. Nesse sentido, supomos que estes saberes e conhecimentos não representam, necessariamente, a existência de um trabalho mais colaborativo ${ }^{18}$. Ao contrário, é provável que a valorização do trabalho em equipe esteja relacionada à posição hierárquica. Se os

16 Empreendemos uma análise sobre o conceito de ubiquidade e suas implicações nas atividades dos docentes que atuam na EaD. Essas ponderações estão presentes na dissertação de mestrado intitulada "Organização do Trabalho Docente na Educação a Distância: implicações da polidocência no contexto da Universidade Aberta do Brasil (UAB)" (VELOSO, 2018).

17 Em nosso estudo, verificamos que $60 \%$ dos docentes-autores/conteudistas e $44,18 \%$ dos docentes-formadores/aplicadores utilizam a sabedoria referente ao trabalho em equipe com muita frequência na EaD. Nossa pesquisa também mostra que $71,74 \%$ dos docentes-tutores virtuais e $85,07 \%$ dos docentes-tutores presenciais utilizam essa mesma sabedoria com muita frequência no contexto do trabalho polidocente. Ou seja, os docentes-tutores (presenciais e virtuais) valorizam mais os saberes e conhecimentos atinentes ao trabalho em equipe do que os demais educadores.

18 Os docentes-formadores/aplicadores são, via de regra, responsáveis por coordenar a equipe de docentestutores. Seria lógico, portanto, que eles valorizassem os saberes e conhecimentos sobre o trabalho em equipe tanto quanto os outros profissionais, afinal, eles são responsáveis por coordenar uma equipe de docentes na polidocência. Mas, ao contrário, nossa pesquisa desvela que os docentes-formadores/aplicadores são os que menos utilizam a sabedoria do trabalho em grupo se comparados aos outros trabalhadores. Exatamente por isso, conjecturamos que os resultados de nosso estudo têm que ver com a percepção dos entrevistados quanto às relações de poder, ou seja, às relações hierárquicas na EaD. 
docentes-tutores, sobretudo os presenciais, situam-se num plano inferior dentro da hierarquia presente na $\mathrm{EaD}$, acabam, por consequência, tendo que lidar constantemente com as imposições e com a subordinação de suas atividades a de outros profissionais. Quer dizer que eles valorizam mais os saberes e conhecimentos sobre o trabalho em equipe, porque suas funções devem estar em consonância com as exigências e às funções de outros docentes. Mesmo que as atividades dos docentes-formadores/aplicadores dependam de uma equipe multidisciplinar e também dos docentes-tutores, eles atuam, comumente, como coordenadores de disciplina. Dessa forma, não valorizam tanto os saberes e conhecimentos relativos ao trabalho em equipe quanto os docentes-tutores, pois suas funções, no contexto da polidocência, não dependem habitualmente da aprovação de outros profissionais docentes. Isto é, conjecturamos que eles acabam lidando de maneira menos acentuada com conflitos de interesse e estão menos subordinados às atividades de outros trabalhadores ${ }^{19}$.

Evidentemente, não desconsideramos que o trabalho em equipe é característico da EaD desenvolvida no âmbito do Sistema UAB. Mill (2012, p. 36) afirma que "na educação virtual, tanto para alunos quanto para docentes, o trabalho em equipe é fundamental para que os objetivos educacionais sejam atingidos". Nossa pesquisa evidencia que um número expressivo de profissionais de todos os perfis docentes utiliza com muita frequência a sabedoria do trabalho em equipe. Contudo, essa utilização é ainda maior para os docentes-tutores virtuais e, principalmente, para os docentes-tutores presenciais. Portanto, acreditamos que, não por acaso, os profissionais que mais se utilizam desses saberes e conhecimentos são também aqueles que possuem menor poder no contexto do trabalho polidocente. Decerto, outros estudos são necessários para aprofundar essas análises. Estudos estes que transcendem as páginas deste trabalho, mas que permeiam nossas pretensões e farão parte de empreendimentos futuros.

\section{CONSIDERAÇÕES FINAIS}

A docência na Educação a Distância é em demasia intrincada. Compreende um trabalho dividido e fragmentado ao passo que apresenta aspectos de uma gestão menos centralizada, resultando em atividades cooperativas e interdependentes. Grosso modo, a docência na EaD, mesmo que dividida, não é estanque, de modo que há, em muitas experiências, uma atuação colaborativa entre os profissionais. Mas isso não significa que esta mesma atuação deva prescindir de relações hierárquicas com vistas a conduzir o processo de trabalho.

19 Trata-se de proposições iniciais, estabelecidas a partir da revisão bibliográfica e de alguns dos resultados de nossa investigação. Certamente, são necessários outros estudos para aprofundar nossas conjecturas. Portanto, contentamo-nos em trazer apenas problemáticas que poderão subsidiar ou nortear outras pesquisas na área. 
Nesse sentido, os resultados de nossa pesquisa indicam que os docentes não apenas percebem relações de hierarquia como também as consideram importantes às atividades na EaD. Consequentemente, estabelecem-se relações de poder indissociáveis às de saber, na medida em que o processo de ensino-aprendizagem demanda uma colaboração de profissionais com formações e conhecimentos distintos.

Identificamos, a partir dos resultados deste estudo, que a titulação dos docentes têm que ver com seu papel exercido no contexto da polidocência. Logo, trabalhadores com mestrado e/ou doutorado possuem, em sua maioria, experiência como autores/conteudistas e formadores/aplicadores. Em contrapartida, grande parte dos tutores (virtuais e presenciais) não possui pós-graduação stricto senso. Nossa investigação indica, ainda, que muitos destes profissionais encontram na tutoria um caminho para adquirir experiência na EaD, enriquecer o currículo, atuar no ensino superior etc.

Portanto, a tutoria, na forma como foi instituída no âmbito do Sistema UAB, parece assegurar as relações de poder que se estabelecem na polidocência e que são consideradas importantes inclusive pelos próprios profissionais. Dessa forma, como docentes que anseiam por experiência profissional e que, em tese, possuem menor titulação, os tutores se encontram mais suscetíveis às relações de poder que acontecem na EaD. Este mesmo poder parece, inclusive, extraterroritorial, uma vez que recorre a mecanismos que o legitimam para além do espaço físico das universidades. Se a EaD acontece em um não-lugar, é lógico que a modalidade recorra a formas de dominação que transcendem aquelas estabelecidas nas sociedades ditas disciplinares.

No entanto, o trabalho polidocente também parece personificar a figura do poder num docente-formador/aplicador - em algumas experiências também num docente-autor/ conteudista - que é o responsável por conduzir as atividades de tutoria. Quer dizer, pois, que a EaD apresenta características calcadas, concomitantemente, nas sociedades disciplinares e de controle. Ora, reconhecemos que estas são proposições iniciais que visam tão somente nortear ou subsidiar estudos mais aprofundados. Estudos estes que se mostram sobremaneira pertinentes à polidocência e à forma como o trabalho docente tem se configurado em cursos a distância no Brasil. 


\section{REFERÊNCIAS}

BELLONI, Maria Luiza. Educação a Distância. 3. ed. Campinas: Autores Associados, 2003, 115 p.

CANTANHEDE, César. Organização do trabalho. 9. ed. São Paulo: Atlas S. A., 1973, 258 p.

CATTANI, Antonio D. Gestão participativa. In: CATTANI, Antonio D. (org.). Trabalho e tecnologia: dicionário crítico. Petrópolis: Vozes, p. 107-114, 1997.

COSTA, Rogério da. Sociedade de controle. São Paulo em Perspectiva, São Paulo, v. 18, n. 1, p. 161-167, jan.-mar. 2004. Disponível em: <http://www.scielo.br/pdf/spp/v18n1/22238.pdf>. Acesso em: 24 nov. 2017.

DIAS, Reinaldo. Sociologia das organizações. São Paulo: Ática, 2008.

DUARTE, Teresa. A possibilidade de investigação a três: reflexões sobre a triangulação (metodológica). CIES e-WorkingPaper, Lisboa, n. 60, p. 1-24, 2009.

KENSKI, Vani M. Avaliação e acompanhamento da aprendizagem em ambientes virtuais, a distância. In: MILL, Daniel; PIMENTEL, Nara (Org.). Educação a Distância: desafios contemporâneos. São Carlos: EdUFSCar, 2013, p. 59-68.

MATTEI, Giovana. A produção da subjetividade e as relações de poder na escola: uma reflexão sobre a sociedade disciplinar na configuração social da atualidade. Revista Educação Especial, Santa Maria, v. 21, n. 31, p. 75-84, maio.-ago. 2008. Disponível em: < https://periodicos.ufsm.br/ educacaoespecial/search/authors/view?firstName=Giovana\&middleName=\&lastName=Mattei\&affiliation=Universidade\%20de\%20Passo\%20Fundo\&country=BR>. Acesso em: 29 set. 2017.

MILL, Daniel. Docência virtual: uma visão crítica. Campinas: Papirus, 2012, 304 p.

MILL, Daniel. Sobre o conceito de polidocência ou sobre a natureza do processo de trabalho pedagógico na educação a distância. In: MILL, Daniel; RIBEIRO, Luis R. C.; OLIVEIRA, Marcia R. G. (Orgs.). Polidocência na Educação a Distância: múltiplos enfoques. São Carlos: EdUFSCar, 2014, p. 25-42.

MILL, Daniel; FIDALGO, Fernando. Estudo sobre relações de saber em sistemas de educação a distância virtual. Perspectiva, Florianópolis, v. 22, n. 1, p. 227-256, jan.-jun. 2004. Disponível em: <https://periodicos.ufsc.br/index.php/perspectiva/article/download/10099/9320>. Acesso em: 08 nov. 2017.

MILL, Daniel; FIDALGO, Fernando. Estudo sobre relações de trabalho em sistemas de Educação a Distância mediada por tecnologias da informação e comunicação. Trabalho \& Educação, Belo Horizonte, n. 11, p. 85-113, jul.-dez. 2002.

NEVES, Inajara de S. V. Diálogos sobre EaD e práticas pedagógicas. In: NEVES, Inajara de S. V.; CORRADI, W.; CASTRO, Carmem L. F. de (Org.). EaD: diálogos, compartilhamentos, práticas e saberes. Barbacena: Eduemg, 2016, p. 15-24.

PRATA, Maria R. dos S. A produção da subjetividade e as relações de poder na escola: uma reflexão sobre a sociedade disciplinar na configuração social da atualidade. Revista Brasileira de 
Relações de saber e poder na Educação a Distância...

Educação, Rio de Janeiro, n. 28, p. 108-116, jan.-abr. 2005. Disponível em: <http://www.scielo.br/ pdf/rbedu/n28/a09n28.pdf>. Acesso em: 29 set. 2017.

SILVA, Lorena H. da. Trabalho a domicílio. In: CATTANI, Antonio D. (org.). Trabalho e tecnologia: dicionário crítico. Petrópolis: Vozes, p. 275-278, 1997.

SILVA, Rosalina C. da. A falsa dicotomia qualitativo-quantitativo: paradigmas que informam nossas práticas de pesquisa. In: ROMANELLI, Geraldo; BIASOLI-ALVES, Zélia M. M. (Org.). Diálogos metodológicos sobre prática de pesquisa. Ribeirão Preto: Legis Summa, 1998. p. 159-174 